\title{
Cutaneous larva migrans imported from a tropical trip - Case report and literature review
}

\author{
Roland Wesołowski ${ }^{1, A-F} \oplus$, Celestyna Mila-Kierzenkowska ${ }^{1, A-F \oplus}$, Marta Pawłowska ${ }^{1, B, D, F \oplus}$, \\ Karolina Szewczyk-Golec ${ }^{1, D-F} \oplus$, Lucyna Kałużna ${ }^{2, A-B, F} \oplus$, Alina Maria Woźniak ${ }^{1, A, E-F} \oplus$ \\ ${ }^{1}$ Department of Medical Biology and Biochemistry, L. Rydygier Collegium Medicum in Bydgoszcz, Nicolaus Copernicus \\ University in Toruń, Bydgoszcz, Poland \\ 2 Department of Cosmetology and Aesthetic Dermatology, L. Rydygier Collegium Medicum in Bydgoszcz, Nicolaus \\ Copernicus University in Toruń, Bydgoszcz, Poland \\ A - Research concept and design, B - Collection and/or assembly of data, C - Data analysis and interpretation, \\ $D$ - Writing the article, E - Critical revision of the article, F - Final approval of article
}

\begin{abstract}
Wesołowski R, Mila-Kierzenkowska C, Pawłowska M, Szewczyk-Golec K, Kałużna L, Wozniak AM. Cutaneous larva migrans imported from
\end{abstract} a tropical trip - Case report and literature review. Ann Agric Environ Med. 2021; 28(4): 709-712. doi: 10.26444/aaem/131600

\section{Abstract}

Introduction. Cutaneous larva migrans (CLM) is a zoonotic disease caused by hookworms characteristic of tropical and subtropical regions. In Poland, new cases appear every year in patients who have travelled to tropical areas. Most of the cases are initially under-diagnosed, which results in a delay in starting proper treatment.

Case report. A 49-year-old woman presented to the Outpatient Dermatology Clinic with a pruritic and fibrous cutaneous lesion on the plantar region of her left foot. She had returned from a tourist trip to Honduras one week before the skin lesion erupted.

Results. The diagnosis of CLM due to Ancylostoma sp. infestation was confirmed. Locally applied cryotherapy was ineffective. The oral treatment of albendazole resulted in complete resolution of the symptoms without recurrence after a 6-month follow up period.

Conclusions. CLM should be considered in travellers to tropical countries. Oral anti-parasitic agents seem to be more effective than topical treatment for dermatosis.

\section{Key words}

Poland, travel, cutaneous larva migrans, zoonosis, hookworm

\section{INTRODUCTION}

Cutaneous larva migrans (CLM) is caused by accidental infestation and migration of animal nematode larvae into the human subcutaneous tissue. It is most frequent in tropical and subtropical regions like Latin America, the Caribbean, South-East Asia and Africa. In Europe, it could be considered as one of the most common dermatosis in patients who have previously travelled to tropical areas [1]. In countries with a temperate climate, such as Poland, CLM is frequently initially under-diagnosed [2]. This results in a delay in starting the proper treatment and quite often leads to the exacerbation of clinical manifestations due to ineffective treatment with topical corticosteroids. The case is presented of CLM as the result of Ancylostoma sp. infection acquired during a tourist trip to Honduras.

\section{CASE REPORT}

A 49-year-old woman presented to the Outpatient Dermatology Clinic with a pruritic, fibrous, severalcentimeter long cutaneous lesion on the plantar region of her left foot. During the examination, the patient informed of her recent trip to a tropical area. She had returned from

Address for correspondence: Karolina Szewczyk-Golec, Department of Medical Biology and Biochemistry, L. Rydygier Collegium Medicum, Nicolaus Copernicus University in Toruń, 24 Karłowicza St, 85-092 Bydgoszcz, Poland E-mail:karosz@cm.umk.pl

Received: 30.10.2020; accepted: 10.12.2020; first published: 30.12 .2020 a holiday to Honduras one week before the skin lesions erupted. At first, the patient had observed itchy redness on the edge of the foot. Because it was a winter season in Poland at the time, the patient was wearing tight-fitting boots, which soon caused the redness to turn into a painful erythematous papule. The patient noticed that the lesion had progressed and was actually wandering in the skin. The patient became worried and decided to consult a dermatologist.

Physical examination demonstrated the characteristic presentation of linear serpiginous skin lesions on the foot (Fig. 1a). The initial diagnosis of cutaneous larva migrans or racing larva (larva currens) was hypothesized and the patient was referred for consultation at the University Center of Maritime and Tropical Medicine in Gdynia, Medical University of Gdansk, Poland. On the basis of the clinical manifestation and history of travel to a country where hookworms are endemic, the diagnosis of CLM caused by Ancylostoma sp. was confirmed. The woman had been on a diving trip to Honduras, thus the accidental transmission of the parasite nematode must have taken place while she was walking barefoot on the wet sand of a beach. The patient was submitted to freezing the leading edge of the cutaneous track with liquid nitrogen. Two days later, a plum-sized, fluid-filled blister, slightly tinted with blood, was noticed on the treated foot (Fig. 1b). This was supposed to be a normal response to cryotherapy. Nonetheless, a dermatological examination two days later revealed a visible track of parasite passage $3 \mathrm{~cm}$ ahead of the healing scab which formed after cryotherapy. The examination which took place on the following day revealed that the fibrous skin eruption had progressed by 


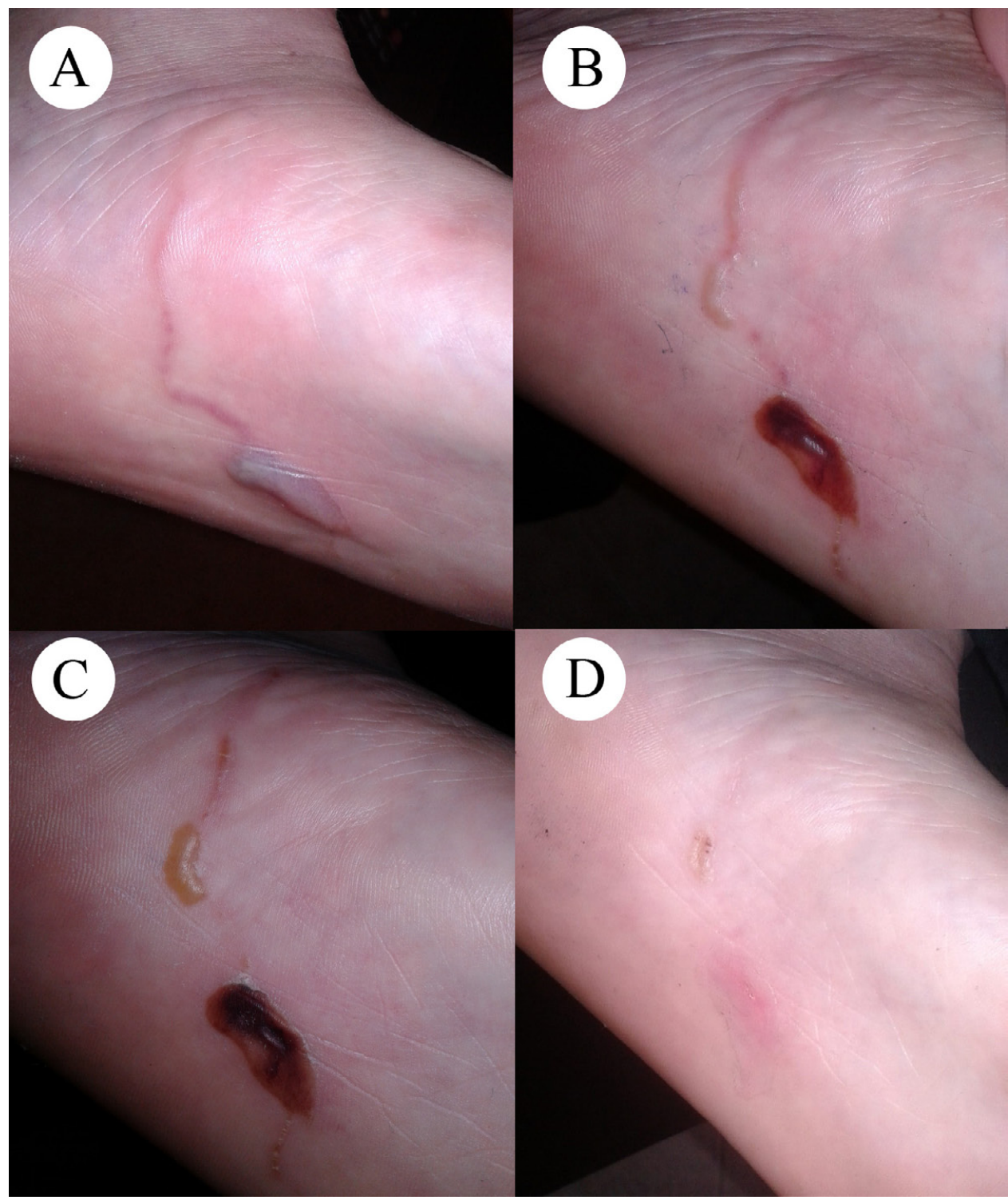

Figure 1. Cutaneous larva migrans syndrome on the plantar region of the left foot of Polish female patient after a touris trip to Honduras. A - characteristic linear elevated serpiginous track with bullous lesion; B - erythematous plaque of cutaneous larva migrans two days after cryotherapy; C - healing process four days after cryotherapy; D - post-treatment photo showing healing

another $1.6 \mathrm{~cm}$. The lesion was swollen, itchy, and painful, and impeded walking, particularly in winter shoes (Fig. 1c). The locally-applied cryotherapy seemed to be ineffective and considering the persistent serpiginous erythema on the sole of foot due to larvae migration, oral treatment was initiated. The patient was administered albendazole, $400 \mathrm{mg}$ per day for 3 days. After oral treatment, the skin lesion stopped wandering and significant improvement was noticed. There were no side-effects of the treatment. A few weeks later, the patient showed complete resolution of the symptoms without recurrence after a follow up period of six months (Fig. 1d).

\section{DISCUSSION}

CLM, formerly synonymous with 'creeping eruption', is a symptom of a zoonotic disease caused by hookworms. CLM is also commonly known as 'ground itch', 'plumber's itch' or 'sandworms' [3]. Disease transmission occurs when the helminth larva, which is present in the contaminated soil, penetrates the skin [4]. The transfer of larvae to human skin from contaminated clothes, towels, or other objects is also possible [5]. Adult hookworms that cause CLM commonly infest the intestine of dogs and cats, which contaminate the soil with their faeces containing the parasite eggs [6]. Under suitable humidity and temperature conditions the larvae mature and hatch from the eggs [7]. The larvae then fed on organic debris and bacteria in the soil, and within several days moult twice to the infective third larval stage (L3). The incubation period is difficult to estimate precisely, but generally in $25 \%$ - $55 \%$ of patients the lesions appear during travel, in others, symptoms appear between 1-145 days after return [5]. Richey et al. [7] reported of a case of CLM caused by Ancylostoma sp. that lasted 22 months before responding to oral thiabendazole therapy. Humans are accidental, dead-end hosts for zoonotic hookworms, which means that the parasites cannot complete their life cycle in the human host. Parasites enter the epidermis but 
are unable to penetrate deeper into the dermis. Therefore, the larvae migrate within the epidermis for a few weeks or months before dying. After penetrating the skin, larvae reside in stratum germinativum, actively producing and secreting a protease and a hyaluronidase, thus aiding their passage through the skin [5]. Invasion of several hookworm larvae at the same time, causing skin lesions in the form of loops and tortuous tracks, may occur. Human hookworms can migrate to other organs and cause systemic symptoms that require systemic treatment. In such cases, parasite eggs can be found in the faeces.

CLM occurs worldwide, but transmission is more common in regions with warm and humid climate [8]. The prevalence of hookworm infections in tropical and subtropical countries reaches up to $95 \%$ [9]. In tropical regions of the world, nematodes of the Ancylostomatidae family are the most common. The most common species of hookworm that infect humans are Necator americanus, Ancylostoma duodenale, Ancylostoma ceylanicum, and exceptionally Ancylostoma caninum and Ancylostoma braziliense [10]. In tropical countries, it is the larva of Ancylostoma braziliense that usually causes CLM in humans [3]. CLM is more common in people who live in poor sanitary conditions, in areas where the soil is contaminated by faeces of hookworm-infected animals. In some regions, such as Malaysia, playground contamination with Ancylostoma eggs reaches up to $88.3 \%$ of tested samples, and is the third most common helminth detected in soil [11]. Europeans usually become infected during a holiday in countries with Ancylostoma endemic prevalence. A worldwide-scale study demonstrated that CLM accounts for over $8 \%$ of all dermatologic problems in returning travellers [12]. According to other studies, it ranges from $5 \%-25 \%$ [13]. Over the last several years, there have been isolated cases of autochthonous infections in European countries [4]. If the global temperature increases further over the next decades, the prevalence of CLM in high-income countries is expected to increase [5].

Ancylostoma spp. infestations in humans manifest in several ways, including itching, erythematous, linear or serpiginous, dermatitis track and moving skin lesion [4]. The speed of larvae migration in the skin varies depending on the species, but typically the distance is less than $1 \mathrm{~cm}$ a day [8]. In some cases, follicular papules and pustules without linear or serpiginous configuration can be observed. There are also uncommon clinical presentations, including hair follicle inflammation in the buttock area, diffuse multifocal papulovesicular eruption mainly on the chest, back and abdomen, or migrating urticaria [14]. The predominant location of lesions are fragments of unprotected skin that come into contact with contaminated soil [5]. CLM complications include secondary bacterial superinfection as a result of scratching, allergic reactions and parasite migration to internal organs [1]. Skin eruptions are the effect of hypersensitivity reaction to parasites and their metabolites. Diagnosis is based on characteristic clinical features supported by a travel history with typical at-risk exposure $[1,2,5]$. The presence of serpiginous exanthems is the most pathognomonic symptom of CLM [8]. An increased number of WBC, with a normal or moderately elevated eosinophil count and normal IgE level is characteristic $[2,15,16]$. Intestinal parasitic infections may be confirmed serologically by an ELISA method for the detection of parasite antigens / coproantigens, or with the use of polymerase-chain reaction (PCR) based methods for detecting hookworm DNA [17]. These molecular techniques are inappropriate for the diagnosis of CLM. However, a case of CLM caused by Ancylostoma caninum, diagnosed serologically by the ELISA method, has been described [15]. In differential diagnosis with the larva currens, caused by Strongyloides stercoralis, the important issue is the speed of larvae migration. In larva currens cases, linear and urticated lesions grow faster than in larva migrans, on average $10 \mathrm{~cm}$ per day. Larvae migrate forward in haphazard manner and lesions persist for only a few hours and generally are localized in the perianal area, on the thighs, and on the trunk. Blackwell and Vega-Lopes [14] analyzed 44 cases of patients diagnosed as having CLM and in almost $73 \%$ of cases the diagnosis was correct. However, approximately $25 \%$ of the patients were diagnosed incorrectly and had received inappropriate treatments.

In temperate countries, CLM is usually underdiagnosed, which results in delayed correct diagnosis, worse clinical course, and the prescription of unnecessary drugs. In the presented case, the serpiginous skin lesions were characteristic for CLM and the disease was diagnosed correctly. Treatment of CLM includes physical modality such as cryotherapy [18] and pharmacologic agents: oral (ivermectin, albendazole, thiabendazole) or topical drugs (thiabendazole) [5]. In cryotherapy treatment, an ethylene chloride spray, liquid nitrogen or carbon dioxide are used [18]. Freezing (3 applications of 10s each) may be applied to small and single lesions, after previous anaesthesia with lidocaine cream [18]. Cryotherapy is often ineffective, as in the presented case, as hookworm larvae are able to survive in temperatures as low as $-21^{\circ} \mathrm{C}$ for longer than 5 minutes [8]. Importantly, the larva is usually $1-2 \mathrm{~cm}$ ahead of the visible tract and can easily be missed during cryotherapy treatment $[8,14]$. For the same reason, surgical treatment to extract migrating larvae is unsuccessful. Veraldi et al. [18] reported that a relapse or no response occurs in $35 \%$ of patients after cryotherapy. Heukelbach and Feldmeier [5] consider that freezing the edge of the track is obsolete, painful and may cause ulcerations. In the pharmacological treatment of CLM, oral thiabendazole and albendazole have often been used, but daily dosage and the length of the therapy is not well established $[3,8]$. An excellent safety profile with no adverse effects during CLM treatment has been reported for a single dose of $200 \mu \mathrm{g} /$ $\mathrm{kg}$ body weight of oral ivermectin; this treatment has been recommended $[3,6,8]$. Another therapeutic scheme is the use of topical thiabendazole (5\%) ointment [3]. Sunderkötter et al. [8] suggest topical albendazole (10\% in lipophilic base) 3 times daily for 7-10 days. Mebendazole (100 mg twice daily for 3 days), with repeated treatment over 2-6 weeks, can also be used for CLM treatment, but it appears to be less effective compared to albendazole, and is not recommended [8]. Anti-histamines and topical corticosteroids are also used for symptomatic relief of pruritus. In some cases, topical treatment of CLM with ivermectin $1 \%$ cream appeared to be effective [19]. Kincaid et al. [20] reported that short-term application of high-dose steroids may provide symptomatic relief of CLM, but prolonged therapy should be avoided. Otherwise, the administration of incorrect drugs may have a negative impact on the disease course, and cause progression of the cutaneous trail in a patient, as in the case described by Akkouche et al. [21]. 


\section{CONCLUSIONS}

As international travels become more and more accessible and common among Polish citizens, there is an increasing risk of contracting tropical dermatosis, including CLM. Travellers to endemic areas should be advised to avoid direct skin contact with the soil and walking barefoot even on the beach. Physicians should consider CLM in patients with characteristic rash, as early diagnosis makes the treatment more successful. Pharmacological antiparasitic treatment seems to be more effective than topical treatment of skin lesions.

\section{REFERENCES}

1. Tekely E, Szostakiewicz B, Wawrzycki B, et al. Cutaneous larva migrans syndrome: a case report. Postepy Dermatol Alergol. 2013; 30(2): 119121. https://doi.org/10.5114/pdia.2013.34164.r

2. Wieczorek A, Szepietowski J. Cutaneous larva migrans. Przegl Dermatol. 2016; 103(4): 292-294. https://doi.org/10.5114/dr.2016.61778.r

3. Cardoso AEC, Cardoso AEO, Talhari C, et al. Update on parasitic dermatoses. An Bras Dermatol. 2020; 95(1): 1-14. https://doi. org/10.1016/j.abd.2019.12.001.r

4. Gutierrez Garcia-Rodrigo C, Tous Romero F, Zarco Olivo C. Cutaneous larva migrans, welcome to a warmer Europe. J Eur Acad Dermatol Venereol. 2017; 31(1): e33-e35. https://doi.org/10.1111/jdv.13621.r

5. Heukelbach J, Feldmeier H. Epidemiological and clinical characteristics of hookworm-related cutaneous larva migrans. Lancet Infect Dis. 2008; 8(5): 302-309. https://doi.org/10.1016/S1473-3099(08)70098-7.r

6. Coello RD, Pazmiño BJ, Reyes EO, et al. A Case of Cutaneous Larva Migrans in a Child from Vinces, Ecuador. Am J Case Rep. 2019; 20: 1402-1406. https://doi.org/10.12659/AJCR.915154.r

7. Richey TK, Gentry RH, Fitzpatrick JE, et al. Persistent cutaneous larva migrans due to Ancylostoma species. South Med J. 1996; 89(6): 609-611. https://doi.org/10.1097/00007611-199606000-00010.r

8. Sunderkoetter C, von Stebut E, Schoefer H, et al. S1 guideline diagnosis and therapy of cutaneous larva migrans (creeping disease). J Dtsch Dermatol Ges. 2014; 12(1): 86-91. https://doi.org/10.1111/ddg.12250.r

9. Indira R, Viveka Vardhani V. Prevalence of ancylostomiasis in people living in slum area, Philhousepet of Eluru, West Godavari District
(Andhra Pradesh). J Parasit Dis. 2013; 37(1): 29-34. https://doi. org/10.1007/s12639-012-0125-0.r

10. Brooker S, Bethony J, Hotez PJ. Human hookworm infection in the 21st century. Adv Parasitol. 2004; 58: 197-288. http://doi.org/10.1016/ S0065-308X(04)58004-1.r

11. Mohd Zain SN, Rahman R, Lewis JW. Stray animal and human defecation as sources of soil-transmitted helminth eggs in playgrounds of Peninsular Malaysia. J Helminthol. 2015; 89(6): 740-747. https://doi. org/10.1017/S0022149X14000716.r

12. Leder K, Torresi J, Libman MD, et al. GeoSentinel surveillance of illness in returned travelers, 2007-2011. Ann Intern Med. 2013; 158(6): 456-468. https://doi.org/10.7326/0003-4819-158-6-201303190-00005.r

13. Korzeniewski K, Juszczak D, Jerzemowski J. Skin lesions in returning travellers. Int Marit Health. 2015; 66(3): 173-180. https://doi. org/10.5603/IMH.2015.0034.r

14. Blackwell V, Vega-Lopez F. Cutaneous larva migrans: clinical features and management of 44 cases presenting in the returning traveller. Br J Dermatol. 2001; 145(3): 434-437. https://doi.org/10.1046/j.13652133.2001.04406.x.r

15. Kwon IH, Kim HS, Lee JH, et al. A serologically diagnosed human case of cutaneous larva migrans caused by Ancylostoma caninum. Korean J Parasitol. 2003; 41(4): 233-237. https://doi.org/10.3347/ kjp.2003.41.4.233.r

16. Veraldi S, Persico MC, Francia C, et al. Chronic hookworm-related cutaneous larva migrans. Int J Infect Dis. 2013; 17(4): e277-e279. http:// dx.doi.org/10.1016/j.ijid.2012.11.002.r

17. Khurana S, Sethi S. Laboratory diagnosis of soil transmitted helminthiasis. Trop Parasitol. 2017; 7(2): 86-91. https://doi.org/10.4103/ tp.TP_29_17.r

18. Veraldi S, Çuka E, Vaira F. Cutaneous Larva Migrans. In: Abramovits W, Graham G, Har-Shai Y, Strumia R, editors. Dermatological Cryosurgery and Cryotherapy. London: Springer; 2016. p. 475-477.r

19. Gerbig AW, Kempf W. Topical treatment of cutaneous larva migrans with ivermectin 1. Int J Dermatol. 2019; 59(1): e21-e22. https://doi. org/10.1111/ijd.14673.r

20. Kincaid L, Klowak M, Klowak S, et al. Management of imported cutaneous larva migrans: a case series and mini-review. Travel Med Infect Dis. 2015; 13(5): 382-387. https://doi.org/10.1016/j. tmaid.2015.07.007.r

21. Akkouche W, Ahmed SA, Sattin A, et al. Autochthonous HookwormRelated Cutaneous Larva Migrans Disease in Northeastern Italy: A Case Report. J Parasitol. 2015; 101(4): 488-489. https://doi.org/10.1645/15725.1 